\title{
USO DE MARCADORES MOLECULARES PARA DETERMINAR A VARIABILIDADE GENÉTICA NO PAPA [SOLANUM TUBEROSUM]
}

\author{
USO DE MARCADORES MOLECULARES PARA DETERMINAR LA \\ VARIABILIDAD GENÉTICA EN PAPA (SOLANUM T'UBEROSUM) \\ (D) Adelfa Yzarra Aguilar ${ }^{*}$, (D) David Ruiz Vilchez ${ }^{1}$, (D) Rene Antonio Hinojosa Benavides ${ }^{2}$, \\ (D) Juan Quispe Rodriguez ${ }^{2}$, (D) Uriel Rigoberto Quispe Quezada ${ }^{2}$, (D) Genaro Mario Condori \\ $\operatorname{Ramos}^{2}$ \\ adelfa.yzarra@unh.edu.pe; david.ruiz@unh.edu.pe; rhinojosa@unah.edu.pe; jquispe@unah.edu.pe; \\ uquispe@unah.edu.pe; gcondori@unah.edu.pe \\ ${ }^{1}$ Universidad Nacional de Huancavelica, Huancavelica, Perú \\ 2Universidad Nacional Autónoma de Huanta, Ayacucho, Perú \\ *Correspondencia: Adelfa Yzarra Aguilar. Email: adelfa.yzarra@unh.edu.pe
}

Recibido: 07.03.2020 | Aprobado: 09.04.2020

\section{RESUMEN}

O objetivo foi compreender o uso e a importância dos marcadores genéticos utilizados nos estudos de diversidade genética em batatas. As publicações mais relevantes dos últimos vinte anos nas bases de dados SciELO, LILACS e PUBMED foram revisadas, analisando a técnica utilizada, os principais resultados obtidos com o uso e a evolução das principais metodologias de marcação nos últimos anos e uma melhor compreensão das técnicas mais comumente usados, concluindo que as cultivares de batata discriminam com mais precisão os marcadores à base de DNA, uma vez que os marcadores à base de proteínas não discriminam em sua totalidade.

Palabras clave: Marcadores moleculares, batata, análise genética, variação genética.

\section{ABSTRACT}

The objective was to understand the use and importance of genetic markers used in studies of genetic diversity in potatoes. The most relevant publications of the last twenty years were reviewed in SciELO, LILACS and PUBMED databases scrutinizing the technique used, the main results obtained from the use and evolution of the main marking methodologies in recent years and a better understanding of the techniques most commonly used, concluding that potato cultivars discriminate more accurately with DNA-based markers, since protein-based markers do not discriminate in their entirety. Keywords: Molecular markers, potato, genetic analysis, genetic variation. 


\section{INTRODUÇÃO}

Quando falamos sobre tipos de caracterização, descobrimos que existem dois tipos de marcadores genéticos: o morfológico e o molecular (Tanksley, 1983 citado por Azofeifa, 2006). Primeiro, a caracterização e identificação tradicionais de variedades foram baseadas no uso de caracteres morfológicos e / ou agronômicos (Rallo et al., 2002 citado por Lengua, 2018). No entanto, o uso de marcadores morfológicos nas plantas tem muitas limitações, pois sua expressão pode estar sujeita a fatores ambientais ou fenológicos; freqüentemente esses marcadores só podem ser avaliados no nível de toda a planta e quando atingem seu estado adulto (Azofeifa, 2006). Nos anos 50, a eletroforese passou a ser utilizada em estudos de diversidade genética, sendo uma técnica que separa moléculas por sua mobilidade diferencial através de um solvente em um campo elétrico, mas atualmente os avanços da biologia molecular incorporaram novas marcadores, de natureza molecular e mais sensíveis à detecção de alterações no genótipo dos indivíduos, situação que permitiu grandes avanços nesse tipo de estudo (Becerra y Paredes, 2000). Dentro dos marcadores moleculares é mencionada a existência de dois tipos: proteínas (principalmente isoenzimas) e marcadores de DNA; nesse último, temos ISSR, RAPD, AFLP, RFLP, SSR, entre outros (Azofeifa, 2006 citado por Chirinos y Jiménez, 2015).

\section{METODOLOGIA}

Uma revisão sistemática da literatura científica foi realizada usando a pesquisa bibliográfica, fazendo revisões sistemáticas no Banco de Dados Cochrane, bem como nas diferentes Agências de Avaliação de Tecnologias em Saúde da Espanha, através de suas páginas da web e em outros países através do Base de dados INAHTA (rede internacional de agências de avaliação de tecnologia). Da mesma forma, uma pesquisa de artigos publicados sobre essa tecnologia foi realizada em diferentes bancos de dados da literatura biomédica: Cinahl, Medline, Embase, Pascal Biomed. A estratégia de pesquisa no PUBMED foi a seguinte: ("Molecular Markers" OR "PCR" [All Fields]) AND ("Marcadores moleculares" OR “caracterização molecular" OR "DNA markers") OR "técnica molecular". Em termos de projeto, estudos experimentais e observacionais, revisões sistemáticas, meta-análises e relatórios de avaliação estão incluídos.

\section{DEFINIÇÃO}

Para Valadez y Kahl (2000 citado por Móstiga et al., 2019) um marcador refere-se a qualquer proteína, RNA ou molécula de DNA de tamanho ou peso molecular conhecido que serve para monitorar ou calibrar sua separação usando eletroforese ou cromatografia, e um marcador genético como qualquer gene cuja expressão permita um efeito fenotípico que pode ser facilmente detectado (por exemplo, um gene que causa resistência a um antibiótico). Marcadores de DNA são baseados principalmente na análise de diferenças em pequenas sequências de DNA entre indivíduos. As técnicas utilizadas para isso são muito diversas e dão nome aos diferentes tipos de marcadores, que podem ser dominantes ou codominantes (Karp y Edwards, 1998 citado por Azofeifa, 2006).

Alguns exemplos são: Polimorfismo do comprimento dos fragmentos de restrição (RFLP), Amplificação aleatória do DNA polimórfico (RAPD), Polimorfismo no comprimento dos fragmentos amplificados (AFLP), Microssatélites ou sequências 
simples repetidas (SSR), Amplificação aleatória do polimorfismo microssatélites (RAMPO) etc. (Rallo et al., 2002).

\section{TIPOS DE MARCADORES GENÉTICOS}

\section{Baseado em proteínas}

Isoenzymes.- Com o avanço tecnológico nos anos 70, o uso de géis de amido e a coloração histoquímica de proteínas, a existência de isoenzimas, múltiplas formas moleculares dentro de um organismo que catalisam a mesma reação foram demonstradas dentro de um organismo. O efeito de uma modificação alélica pode ser detectado com segurança, devido a uma alteração na mobilidade eletroforética. Essa sensibilidade eletroforética fez com que a técnica revolucionasse os estudos de diversidade genética em várias espécies e, para esses estudos, diversas estruturas vegetais foram utilizadas, como folhas, raízes ou botões de flores, a partir dos quais é obtido um extrato de proteína bruta. A técnica consiste na separação das enzimas do extrato bruto, em um suporte permeável (amido, gel de poliacrilamida) sob a ação de um campo elétrico e seguido por uma coloração histoquímica. A separação é feita pela carga elétrica líquida, peso molecular, ponto isoelétrico e / ou combinação desses critérios (separação multidimensional). Dessa maneira, as enzimas codificadas por diferentes genes ou produtos de diferentes alelos do mesmo gene são separadas (Becerra y Paredes, 2000).

As principais características das isoenzimas incluem simplicidade, quantidade mínima do material em estudo, baixo custo e cobertura genômica de 10 a 20 locos por espécie, ausência de epistasia e influências ambientais. A expressão alélica é codominante, o que permite comparações entre espécies, populações da mesma espécie e detecta a presença de híbridos e introgressão gênica (Paredes y Gepts, 1995 citados por Becerra y paredes, 2000).

Forrest (1994 citado por Soza, 2011) menciona que as isoenzimas provaram ser de grande valor em estudos de melhoria tanto em populações naturais quanto em plantações de árvores e mantêm algum valor de utilidade, especialmente em estudos em larga escala da estrutura da população e em relação à resistência a pragas e doenças. Por exemplo, González et al. (2004) realizaram um estudo sobre a estrutura populacional de palmeiras Phoenix canariensis y Phoenix dactylifera nas Ilhas Canárias, Espanha. Suas desvantagens incluem um baixo nível de polimorfismo, apresentando poucos alelos por locus, especialmente quando a base genética é estreita. Outro aspecto a considerar é que as proteínas, sendo um produto do DNA, podem ser afetadas qualitativa e quantitativamente em seu nível de expressão por fatores ambientais. Para aumentar a eficiência da técnica antes desse fator, devem ser identificados os estágios de desenvolvimento da planta durante os quais a proteína é estável. Além disso, como nas proteínas de reserva, as isoenzimas podem ou não refletir as alterações genéticas que ocorrem no DNA. Além disso, apenas um conjunto de genes estruturais é representado nessas proteínas, ou seja, apenas uma parte do genoma pode ser avaliada.

\section{Baseados em DNA}

\section{Existem três categorias básicas:}


Categoria 1: Métodos que não são baseados na reação em cadeia da polimerase (PCR). Por exemplo, RFLP e número variável de repetições em tandem (VNTRs).

\section{Polimorfismo do comprimento dos fragmentos de restrição (RFLP)}

Valadez y Kahl (2000 citado por Móstiga et al., 2019) eles definem RFLPs como a variação no comprimento dos fragmentos de DNA produzidos por uma endonuclease de restrição específica a partir de DNA genômicos de dois ou mais indivíduos de uma espécie. Os RFLPs são gerados por rearranjos ou mutações que levam à criação de locus de reconhecimento para endonucleases específicas. Essas variações também podem ocorrer devido à presença de ácido desoxirribonucleico (DNA) repetido com diferentes quantidades de cópias em uma região cromossômica específica. O conceito principal era que a mutação no local de restrição ou a mutação que altera a distância entre os locais de restrição adjacentes poderiam ser visualizadas como "marcadores de DNA".

As "enzimas de restrição" são necessárias para realizar a análise. Essas enzimas reconhecem e cortam o DNA em locais específicos. A alta especificidade para reconhecer sequências é a base para a maioria das estratégias de clonagem de DNA. A grande maioria das enzimas de restrição usadas na clonagem molecular reconhece sequências de quatro, cinco ou seis nucleotídeos de comprimento. As RFLPs têm sido amplamente utilizadas em plantas com diferentes objetivos: caracterização de germoplasma, estudos filogenéticos, pureza de sementes híbridas, seleção e / ou localização de genes específicos de importantes características agronômicas, entre outros (Valadez y Kahl, 2000 citado por Móstiga et al., 2019).

Uma das etapas da análise da RFLP inclui um procedimento de eletroforese. Geralmente, a eletroforese é uma comunicação tecnológica para separação, identificação e purificação dos núcleos moleculares. Eles se baseiam no fato de que as moléculas do núcleo são negativas, migratórias, inexistentes e não elétricas. A eletroforese do DNA geralmente é real e uma matriz de agarosa ou poliacrilamida, além de um tampão que permite o estabelecimento de um veículo elétrico, apenas o custo, a tecnologia complexa e a granularidade do DNA necessários são os caminhos limitados à amostra RFLP da técnica de diagnóstico.

Categoria 2: Técnicas que utilizam iniciantes (“primer”) arbitrários ou semiarbitrários. Por exemplo, iniciadores PCR arbitrário múltiplo (MAAP), RAPD, RAMPO.

\section{Reação em cadeia da polimerase (PCR)}

A análise por PCR é um procedimento in vitro para a síntese e duplicação de sequências específicas de DNA. Esta tecnologia utiliza sequências oligonucleotídicas que iniciam a síntese de fragmentos de DNA de comprimentos variados, não maiores que 6 Kb em média (Valadez y Kahl, 2000 citado por Móstiga et al., 2019), essa análise utiliza, de acordo com a técnica, um ou dois oligonucleotídeos sintéticos (iniciadores), geralmente entre 10 e 30 pares de bases e complementares à sequência nucleotídica das extremidades do DNA branco e projetados para hibridizar na direção oposta. O método envolve a execução de uma série repetitiva de ciclos térmicos, cada um dos quais envolve a desnaturação do DNA, a união do iniciador à cadeia desnaturada e a síntese, a partir do 
iniciador, de uma cadeia dupla através da ação do polimerase (Valadez y Kahl, 2000 citado por Móstiga et al., 2019).

A grande maioria dos marcadores moleculares de DNA, atualmente utilizados, é baseada na técnica de PCR, uma vez que essa técnica forneceu um conjunto de marcadores como por exemplo; los RAPDs, SSR, AFLPs, regiões amplificadas de sequências caracterizadas (SCARs), amplificação seletiva de loci polimórficos (SAMPLs), amplificação aleatória de impressões digitais de DNA "DNA Fingerprinting" (RAF) e amplificação direta com DNA microssatélites (DAMD) (Ramage et al., 2004; Saxena et al., 2005). A polimerase dependente de DNA é uma enzima que, sob certas condições e na presença de uma pequena cadeia de DNA, que atua como um primer, é capaz de produzir milhões de cópias de certos fragmentos de DNA. Esses fragmentos são subsequentemente separados por peso molecular e conformação por técnicas eletroforéticas, obtendo um padrão de banda específico que nos permite diferenciar indivíduos (Rallo et al. 2002).

\section{Amplificação aleatória do DNA polimórfico (RAPD)}

Essa análise foi descrita pela primeira vez em 1990, de modo que a modificação que a originou consistiu em substituir a tecnologia de PCR, o uso de um par de "primers" cuidadosamente projetados e levemente longos, por um único iniciador curto, de aproximadamente 10 nucleotídeos de comprimento e sequência arbitrária, com capacidade de se ligar a regiões específicas do genoma (Valadez y Kahl, 2000 citado por Móstiga et al., 2019). Os polimorfismos produzidos com a técnica RAPD são chamados de marcadores RAPD e podem resultar de qualquer alteração na sequência ou no local de ligação do iniciador (mutação pontual), que impede o iniciador de ingressar na cadeia, ou também pode ser o produto de alterações que alteram o tamanho ou impedem a amplificação bem-sucedida do DNA modelo. Como regra geral, o tamanho das variantes é detectado com moderação e os produtos individuais de amplificação representam um alelo por locus. Nos estudos de herança, os produtos de amplificação se comportam como marcadores dominantes (Waugh y Powell 1992 citados por Azofeifa, 2006).

Categoria 3: PCR com site "objetivo específico". Por exemplo, SSR, Inter repetidas sequências simples (ISSR).

\section{Polimorfismo no comprimento dos fragmentos amplificados (AFLP)}

As AFLPs são consideradas marcadores de alta eficiência, permitem a análise de um grande número de loci por experimento, sem a necessidade de informações prévias sobre sua sequência, são predominantemente dominantes e altamente reprodutíveis. No entanto, a técnica é mais complicada de executar do que a do RAPD e SSR, eles também exigem uma quantidade maior de DNA (SIDTA 1999 citado por Azofeifa, 2006). Eles podem ser usados, por exemplo, na construção da estrutura dos mapas genéticos nos quais os marcadores codominantes estão localizados, para discriminar entre indivíduos intimamente relacionados e para localizar genes específicos em genomas complexos (Valadez y Kahl 2000 citado por Móstiga et al., 2019).

A análise de AFLP combina a digestão com enzimas de restrição com a PCR. O primeiro passo envolve a digestão do DNA com duas enzimas de restrição específicas, 
uma das quais corta sequências precisas e a outra corta com mais frequência. É necessário adicionar adaptadores para que fiquem nas bordas dos fragmentos recém-formados e, assim, forneçam uma sequência conhecida para poder amplificar por PCR. Nesta etapa, também é necessário o uso de ligases para facilitar a ligação entre as bordas dos fragmentos e as sequências curtas conhecidas.

Se o primeiro passo fosse realizado adequadamente, todos os fragmentos de restrição seriam amplificados por PCR. Para discriminar entre todos os fragmentos de restrição que são formados, os primers são projetados de forma a incorporar o adaptador de sequência conhecido mais um, dois ou três pares de bases (deixando de fora qualquer um dos quatro possíveis: A, G, C o T). Amplificação por PCR somente ocorrerá nos fragmentos em que os iniciadores encontrarem as sequências complementares para o adaptador e os pares de bases adicionais. Nesse caso, os pares de bases adicionados atuam como nucleotídeos seletivos.

Se apenas um desses nucleotídeos for usado, mais fragmentos serão amplificados do que poderiam ser amplificados se dois nucleotídeos fossem usados. Da mesma forma, se três nucleotídeos forem usados, menos fragmentos amplificados serão obtidos. Durante a PCR, normalmente são realizados dois ciclos térmicos seletivos. No primeiro, um único nucleotídeo seletivo é usado, no segundo ciclo térmico, o nucleotídeo anterior é usado mais um ou dois nucleotídeos seletivos adicionais. Mais detalhes sobre a técnica podem ser encontrados em Valadez y Kahl (2000 citado por Móstiga et al., 2019), que mencionam que as AFLPs surgem de: A) Polimorfismos do local de restrição, onde uma sequência específica para o reconhecimento de uma endonuclease de restrição está presente ou ausente. B) Polimorfismos no comprimento da sequência, em que o número de sequências repetidas organizadas em série ("tandem") possui locais variáveis. C) Alterações nos pares de bases de DNA não associadas a locais de restrição.

\section{Microssatélites simples ou sequências repetidas (SSR)}

Os microssatélites ou sequências simples repetidas (SSR) são regiões de pequenas sequências (de dois a 10 pares de bases) repetidas, dispostas em série, que se supõe distribuídas aleatoriamente por todo o DNA. São sequências de DNA altamente variáveis dispersas pelos genomas de fungos, plantas e animais, que podem ou não estar associados a genes, são loci altamente mutáveis que podem estar presentes em muitos locais do genoma. Como a repetição por si só não codifica para formar nenhuma proteína, e como as sequências repetitivas de DNA podem se recombinar e expandir com mais frequência do que outros tipos de sequências, essas regiões são frequentemente altamente variáveis e consequentemente úteis para medir o polimorfismo entre espécies ou variedades estreitamente relacionadas (Valadez y Kahl, 2000 citado por Móstiga et al., 2019).

Wu y Tanksley (1993 citado por Azofeifa, 2006) eles descobriram que as sequências (GA)n e (GT)n e suas complementos (CT)n y (CA)n elas ocorrem com mais frequência e são espaçadas aleatoriamente no genoma do milho. Eles também observaram que esses locais são altamente polimórficos entre as variedades de arroz, portanto são úteis como ferramentas de mapeamento e para estudos de polimorfismos intraespecíficos. O desenvolvimento de marcadores SSR é muito trabalhoso, porque regiões genômicas específicas (bordas microssatélites) devem ser identificadas e sequenciadas, embora, uma 
vez alcançado, apresente um sistema muito informativo. Sobre isso, Cervera et al. (2002). Eles mencionam que, embora os microssatélites permitam analisar apenas um locus por experimento, eles são bastante informativos, pois permitem que as variantes alélicas sejam diferenciadas dos locus analisados e, portanto, identificam grupos de ligação entre diferentes mapas genéticos. No entanto, para o seu desenvolvimento é necessário conhecer a sequência e, portanto, são menos numerosos do que outros marcadores dominantes.

Esses marcadores são ideais para o estudo da ligação genética em plantas e mapeamento físico, estudos populacionais e identificação de variedades (SIDTA 1999 citado por Azofeifa, 2006). A tecnologia para análise por microssatélites é semelhante à usada para análise RAPD, com a adição de uma avaliação e sequenciamento anteriores para determinar os iniciadores. A detecção do polimorfismo SSR é realizada por PCR e a separação dos produtos por eletroforese em agarose, poliacrilamida ou géis sequenciadores. As variações detectadas pelos SSRs são o resultado de alterações no número de unidades repetidas (Lowe et al., 2004).

Uma técnica derivada da anterior é conhecida como "PCR iniciada com microssatélites ancorados (AMP-PCR)" que utiliza primers com "âncoras" nas extremidades 3 'ou 5'. Essa classe de iniciadores consiste em uma, duas ou três bases adicionais para o microssatélites, por exemplo; C(CT)8, CA(CT)8, CAC(CT)8 o (CT)8C, (CT)8CA y (CT)8CAC e servem para selecionar as ilhas microssatélites no genoma flanqueadas com o complemento de bases específicas, por exemplo; T(TA)8, GT(GA)8, GTG(GA)8 o (GA)8G, (GA)8GT y (GA)8GTG, então sua especificidade é aumentada (Valadez y Kahl 2000 citado por Móstiga et al., 2019).

Essa técnica é mais eficiente que as técnicas SSR ou RAPDs, pois detecta mais variabilidade genética.

\section{EXEMPLOS E USOS DE MARCADORES MOLECULARES EM ESPÉCIES VEGETAIS}

Marcadores moleculares são a principal ferramenta usada hoje em microorganismos, plantas e animais para: caracterização de germoplasma, identificação de genótipo, determinação de pureza, análise de diversidade genética, melhoria genética assistida por marcadores, isolamento e caracterização de genes específicos a serem utilizados na transformação genética, construção de mapas de ligação, na identificação de transformantes individuais ou sua progênie, entre outros. Abaixo está uma série de exemplos gerais:

\section{Exemplo de isoenzimas}

Harris et al. (1994 citados por Azofeifa, 2006), eles avaliaram a variabilidade genética de Leucaena leucocephala (Lam.). Em 24 populações de diferentes países, usando uma análise de isoenzima. Com o uso de três sistemas de isoenzimas (aspartato aminotransferase, peroxidase e glicose-6-fosfato isomerase) foi possível identificar fenótipos multe enzimáticos e, dessa forma, foi possível identificar duas subespécies de L. leucocephala, além de diferenciar populações; enquanto Hawkins et al. (2001) eles usaram a análise de isoenzimas, RAPD e SSR para construir um mapa de ligação para populações de melancia 
F2 e F3 (Citrullus lanatus) derivadas da cultivar New Hampshire Midget, suscetível a Fusarium oxysporum, e cultivar resistente PI 296341-FR.

\section{Exemplo de RFLP}

As RFLPs têm sido usadas como marcadores de caracteres agronômicos de grande interesse em espécies de gramíneas e leguminosas, no estudo de ligações de pólen e estilo e incompatibilidades em espécies como maçã, cereja e na identificação de resistência a doenças em cevada, milho, etc. (SIDTA 1999 citado por Azofeifa, 2006).

Mayes et al. (2000) usaram marcadores RFLP para avaliar a diversidade genética em 54 palmeiras de óleo; essas palmeiras representam a maioria dos pais nos cruzamentos realizados nos programas de melhoramento, obtendo um total de 157 bandas a partir das quais foi calculada a distância genética entre as palmeiras. A análise molecular corresponde corretamente à origem e à linhagem esperada; esses autores destacaram o potencial de marcadores em programas de melhoramento, através do exame da estrutura genética de um grupo de plantas para estimar os cruzamentos que podem ser feitos com maior ou menor sucesso, permitindo conhecer o pool genético dos pais cruzar e estimar a descendência, bem como avaliar a fidelidade genética da descendência.

N'Goran et al. (2000), Através do uso de marcadores RFLP, eles analisaram a estrutura genética de 175 genótipos de Theobroma cacao L. da América Central e do Sul. Essa análise permitiu determinar: uma alta diversidade genética entre os materiais, que o número de alelos por locus nunca foi maior que quatro, que os genótipos da América Central são diferentes dos da América do Sul e que, dentro de uma população, a diversidade de genes é alta.

Com o uso da técnica RAPD, foi avaliada a estabilidade genética das seleções regeneradas in vitro de Annona cherimola e Annona muricata. 29 iniciadores foram avaliados, seis deles foram selecionados pelo seu padrão de repetição em ambas as espécies e seleções. Os resultados confirmaram a estabilidade genética das plantas micro propagadas de acordo com os iniciadores selecionados

Salazar y Efraín (2002) caracterizaram os genótipos de cacau pertencentes à coleção 95 da Estação Experimental Ocumare de la Costa, na Venezuela, com o uso de marcadores RAPD e seus resultados permitiram a classificação dos cacaueiros em dois grupos; Cacaos crioulos antigos e cacaus crioulos atuais, além disso, foi evidenciado que os materiais provenientes da mesma localidade apresentam padrões de banda semelhantes e formam grupos locais, possivelmente por apresentar uma origem comum. Esses mesmos autores extraíram diferentes tipos de tecido foliar; tenros e frescos, temperados e frescos, tenros e armazenados, em congelamento e tempero e armazenados em congelamento para extrair DNA e caracterizar a população de cacaueiros; determinando que o tecido ideal para a extração é o tecido jovem e fresco, pois apresenta menos problemas de oxidação e conteúdo de mucilagem nas amostras processadas, o que favorece o processo de extração de ácidos nucleicos.

\section{Exemplo de AFLP}

Eiadthong et al. (2000) analisaram a relação filogenética entre 14 espécies de Mangifera, comparando 217 marcadores AFLP. Para a análise, eles usaram os métodos 
UPGMA (método de agrupamento de pares não ponderados usando médias aritméticas) e NJ (junção de vizinhos). Além disso, marañón (Anacardium occidentale) e gandaria (Bouea macrophylla) foram incluídos como grupos externos. Eles descobriram que a manga comum está intimamente relacionada a Mangifera sylvatica, Mangifera laurina e Mangifera oblongifolia. A variação intraespecífica entre sete cultivares de manga comum foi menor que a variação interespecífica e essas cultivares foram incluídas no mesmo grupo de Mangifera indica nos dois métodos utilizados. Mangifera macrocarpa, Mangifera foetida e Mangifera odorata também estão bastante relacionadas com Mangifera indica de acordo com UPGMA e NJ. No entanto, essas três espécies são classificadas em um subgênero diferente (Limus subgênero) e Mangifera indica pertence ao subgênero Mangifera.

Garcia-Mas et al. (2000) avaliaram três tipos de marcadores moleculares; AFLP, RAPD y RFLP para medir a diversidade genética entre seis variedades de melão (pele de sapo, Ogen, PI161375, PI414723, Agrestis y C105). A análise dos grupos (“cluster") realizados com os três tipos de marcadores, eles separam os genótipos em dois grupos principais: (1) os do tipo doce, que são os melões cultivados (pele de sapo e Ogen) e (2) os tipos exóticos e não cultivados (outros genótipos) Com os dados obtidos, concluiu-se que os três tipos de marcadores utilizados são informativos e que o marcador AFLP oferece a maior eficiência na detecção de polimorfismos.

\section{Exemplo de SSR}

Crouch et al. (2000b) eles construíram iniciadores das regiões genômicas que fazem fronteira com vários microssatélites de Musa com a idéia de detectar polimorfismo nos materiais da coleção. Com a especificidade dos "primers" desenvolvidos, foi possível distinguir entre os vários materiais de germoplasma; por exemplo, híbridos triploides e tetraploides de famílias híbridas de bananas. Além disso, os marcadores permitiram demonstrar a ocorrência de recombinação durante a formação de gametas $2 \mathrm{n}$ a partir de bananas triploides e a heterozigose de uma adesão de banana comumente usada como genótipo "fiel ao tipo" em estudos genéticos. Lai et al. (2001) analisaram 37 amostras de chá (Camellia sinensis) da China, Assam e Taiwan, usando microssatélites, e com as informações obtidas, determinaram que a diversidade de genes de intrapopulação é maior que a interpopulação e que a maior diversidade dentro de uma população ocorre nos materiais Terras selvagens de Taiwan. Além disso, eles desenvolveram um dendograma, mostrando que o chá nativo de Taiwan está intimamente ligado aos materiais de Assam, depois aos materiais da China e aos híbridos de Taiwan.

\section{CONCLUSÕES}

A diversidade genética pode ser detectada entre cultivares de batata para diferenciar essas culturas por meio de marcadores genéticos, seja com marcadores morfológicos ou moleculares. As cultivares de batata discriminam mais precisamente os marcadores moleculares, embora os marcadores morfológicos não discriminem em sua totalidade. É importante selecionar linhas baseadas na diversidade genética de parâmetros agro morfológicos, com a ajuda de marcadores moleculares, para que os programas de melhoramento sejam eficazes, uma vez que a variabilidade genética em espécies de batata cultivadas é de extrema importância para garantir a alimentação de agricultores e famílias 
de camponeses, dada a diversificação de ambientes e riscos climáticos adversos, especialmente na região andina.

\section{REFERÊNCIAS BIBLIOGRÁFICAS}

Azofeifa A. (2006). Uso de marcadores moleculares en plantas; aplicaciones en frutales del trópico. Agronomía Mesoamericana, vol. 17, núm. 2, julio-diciembre, 2006, pp. 221-241

Becerra V. y Paredes M. (2000). Uso de marcadores bioquímicos y moleculares en estudios de diversidad genética. Agricultura Técnica 60(3):270-281.

Brown J., Laurentin H. y Dávila M. (2003). Genetic relationship between Annona muricata L. accessions using RAPD markers. Fruits 58(5)255-259.

Cervera M., Cabezas J. y Martínez J. (2002). Análisis genético de la vid. Madrid, España.

Crouch H.K., Crouch J.H., Madsen S., Vuylsteke D.R. y Ortiz R. (2000a). Comparative analysis of phenotypic and genotypic diversity among plantain landrace (Musa spp., AAB, group). Theoretical and Applied Genetics 101(7):1056-1065.

Crouch J., Ortiz R., Crouch H., Jarret R., Fordlloyd B., Howell E., Newbury H., Craenen K., Karamura E. y Vuylsteke D. (2000b). Utilization of molecular genetic techniques in support of plantain and banana improvement. Acta Horticulturae 540:185-191.

Chirinos M.C. y Jiménez J.E. (2015). Transferencia de algunos marcadores moleculares microsatélites de la familia Fabaceae en tarwi (Lupinus mutabilis Sweet), Scientia Agropecuaria 6 (1): 51 - 58 (2015)

Eiadthong W., Yonemori K., Kanzaki S., Sugiura A., Utsunomiya N., Subhadra-Bandhu S. y Suranant S. (2000). Amplified fragment length polymorphism analysis for studying genetic relationships among Mangifera species in Thailand. Scientia Agriculture Sinica 33(3):19.

García-Mas, j., Oliver M., Gomez-Paniagua H. y Vicente M. (2000). Comparing AFLP, RAPD and RFLP markers for measuring genetic diversity in melon. Theoretical and Applied Genetics 101(5-6):860-864

Hawkins L.K., Dane F., Kubisiak T.L., Rhodes B.B. y Jarret R.L. (2001). Linkage mapping in a watermelon population segregating for fusarium wilt resistance. Journal of the American Society for Horticultural Science 126(3):344-350.

Lai J., Yang W. y Hsiao J. (2001). An assessment of genetic relationships in cultivated tea clones and native wild tea in Taiwan using RAPD and ISSR markers. Botanical Bulletin of Academia Sinica 42(2):93-100.

Lengua R.G. (2018). Caracterización molecular de las colecciones nacionales de ajíes Capsicum spp. del Instituto Nacional de Innovación Agraria (INIA) y la Universidad Nacional Agraria la Molina (UNALM), mediante marcadores moleculares. Lima, Perú. 
Lowe A., Harris S. y Ashton P. (2004). Ecological genetics; design, analysis, and application. Blackwell Science. Victoria, Australia. 326 p.

Mayes S., Jack P., Corley R., Nei M. y Li W. (2000). The use of molecular markers to investigate the genetic structure of an oil palm breeding programme. Heredity 85(3):288.

Móstiga R., Cano B., Quispe L. y Móstiga M. (2019). Análisis morfológico y molecular de especies de bambú del género Guadua procedentes de las regiones San Martín y Cajamarca, Perú. Revista de Investigación en Agroproducción Sustentable, 3(1), 83 91.

N`Goran J, Laurent V., Risterucci A. y Lanaud C. (2000). The genetic structure of cocoa populations (Theobroma cacao L.) revealed by RFLP analysis. Euphytica 115(2):83-90.

Rallo P., Belaj A., De La Rosa, R. y Trujillo I. (2002). Marcadores moleculares. Córdoba, España. http://www.extremadura21.com/caudal/hemeroteca/mayo-junio_2000/ almazara/almazara1.htm

Ramage C., Sando L., Peace C.P., Carroll B.L. y Drew R. (2004). Genetic diversity revealed in the apomictic fruit species Garcinia mangostana L. Euphytica 136(1):1-10.

Salazar Y. y Efrain G. (2002). Caracterización molecular de genotipos de mango y cacao. Aragua. Venezuela. http://www.bcar.bib.ve

Saxena S., Chandra R. C., Srivastava A.P., Mishra M., Pathak R.K. y Ranade S.A. (2005). Analysis of genetic diversity among papaya cultivar using Single Primer Amplification Reaction (SPAR) methods. The Journal of Horticultural Science and Biotechnology 80(32):291-296.

Soza W. (2011). Determinación de la variabilidad genética de cinco poblaciones naturales de Cedrela odorata l. en Nicaragua, usando marcadores RAPDs y morfológicos. Tesis. Universidad Nacional Autónoma de Nicaragua.

\section{CITAR COMO:}

Yzarra Aguilar, A., Ruiz Vilchez, D., Hinojosa Benavides, R. A., Quispe Rodriguez, J., Quispe Quezada, U. R., \& Condori Ramos, G. M. (2020). Uso de marcadores moleculares para determinar a variabilidade genética no papa (solanum tuberosum). Puriq, 2(2), 81-91. https://doi.org/10.37073/puriq.2.2.71 